\title{
REMOCIÓN DE ARSÉNICO EN AGUAS SUBTERRÁNEAS CON BAJAS CONCENTRACIONES DE HIERRO MEDIANTE MICROFILTROS COMERCIALES
}

\section{Ramiro Escalera Vásquez}

\section{RESUMEN}

Se ha monitoreado el desempeño de un sistema de filtración para la remoción simultánea de As y Fe durante 40 días, en aguas de pozo con bajas concentraciones de Fe total. El sistema está compuesto por un tanque de aireación provisto de un aspersor comercial y dos microfiltros comerciales de polipropileno ( $5 \mu \mathrm{m}$ de tamaño de poro) dispuestos en serie. También se ha estudiado la remoción simultánea de hierro total y arsénico total en la trayectoria del sistema de aducción de agua hacia el sistema de aireación-filtración. Existen significativos porcentajes de remoción de Fe total (hasta un $42 \%$ ) y As total (hasta un 75\%) en la trayectoria de la aducción de agua que va hacia el sistema de aireación - filtración.

Las características del agua del pozo del establecimiento educativo son apropiadas para la remoción simultánea de Fe y As, por su moderada concentración de $\mathrm{Ca}^{2+}, \mathrm{pH}$ neutro y bajas concentraciones de nitratos y sulfatos que podrían competir con los arseniatos por los sitios de adsorción de los hidróxidos de hierro retenidos en los medios filtrantes. Aun cuando la concentración de Fe en las aguas sin tratar son relativamente bajas $(<0,3 \mathrm{mg} / \mathrm{l})$, existe una significativa acumulación de ferrihidrita, $\mathrm{Fe}(\mathrm{OH})_{3}$ sobre la superficie de los microporos de los medios filtrantes, llegando hasta concentraciones entre 53 y $70 \%$, medidas como $\mathrm{Fe}_{2} \mathrm{O}_{3}$, de la masa total de sólidos retenidos.

Las eficacias de remoción de As total y $\mathrm{Fe}$ total en el sistema fueron significativas $(33-41 \%$ y $46-78 \%$, respectivamente), aprovechando solo la presencia de Fe total filtrable en las aguas subterráneas, por lo que se puede considerar que el sistema de filtración es apropiado para tasa de consumo hasta de $160 \mathrm{l} / \mathrm{d}$, bajo las condiciones descritas. La eficacia de remoción de As total es menor que la lograda en el sistema piloto de tratamiento basada en colectores solares, debido principalmente a la adición de altas concentraciones de sales de hierro.

Palabras Clave: Remoción Simultanea de Arsénico y Hierro, Aireación, Micro-filtración. 